\title{
Microwave assisted Soxhlet extraction of essential oil from Vietnamese Star anise fruits (IIlicium verum Hook.f.) and their chemical composition
}

\author{
Phan Nhut Nam¹, Phan Thi Kim Lien², Tran Thanh Hoa ${ }^{3}$, Chatain Mai Huong ${ }^{4}$, Dao Thien²* \\ ${ }^{1}$ Faculty of Applied Sciences, Ton Duc Thang University, Vietnam, ${ }^{2}$ Faculty of Food Technology, Ho Chi Minh City University of Food Industry, \\ Vietnam, ${ }^{3}$ Cai Lan Oils \& Fats Industries Company, Vietnam, ${ }^{4}$ Laboratoire BioDymia, ISARA-Université Lyon 1, France
}

\section{A B S T R A C T}

\begin{abstract}
The influence of microwave power (W), irradiation time (h) and particle size (P) on the yield of extraction and composition of essential oil from Illicium verum Hook. $f$ has been assessed by means of a new experimental design. The combined effects of three factors above on the yield of extraction of essential oil Y\% (r.m) have been determined using Doehlert matrices in the range of $100-400 \mathrm{~W}$ for microwave power, $10-40$ mins for irradiation time and $0.4-2.0 \mathrm{~mm}$ for particle size. In these conditions, second order polynomial relationship between $Y \%(\mathrm{r} . \mathrm{m})$ and these factors have been established with regression coefficients close to 0.93. The major effect of microwave power and particle size on the yield of extraction of essential oil has been highlighted. In the conditions of $325 \mathrm{~W}$ microwave power, $20 \mathrm{~min}$ irradiation time and $0.4 \mathrm{~mm}$ particle sizes, the highest essential oil yield by microwave assisted Soxhlet extraction was $8.3 \%$. The main compound of Illicium verum Hook.f was the (E)-anethole (92\%). The composition of $\alpha$-pinene, $\beta$-mycrene, $\alpha$-phellandren were absent from the essential oil extracted from Illicium verum Hook. f. by use of MASE.
\end{abstract}

Keywords: Microwave assisted extraction (MAE); Extraction; Essential oil; Illicium verum Hook. f.; Star anise fruits; Doehlert matrices

\section{INTRODUCTION}

Star anise (Illicium verum Hook. f.) fruits is referred to as aromatic evergreen tree. This plant is one of the most important essential-oil trees grown in Northern Vietnam (Wei et al., 2014; Nguyen et al., 2012; Dang and Ilangantileke, 1997; Loi and Thu, 1970. It is often used not only as a flavor in Vietnamese cuisine (Nguyen et al., 2012; Dang and Ilangantileke, 1997; Loi and Thu, 1970) but also an element of the traditional spice powder of Chinese cooking. It is applied in variety of the Vietnam's traditional foods like Pho bo soup (Chempakam and Balaji, 2008). The essential oil extracted from Star anise fruits is applied as aroma in cookies, biscuits and in treating colic and rheumatism (Claus and Tyler, 1965). Star anise has been used as a medicinal plant for a long time in Vietnam. Moreover, the crude fruits and its powder both are used in traditional teas in order to treat nervousness and sleeplessness,etc. The essential oil from this fruits is used for treatment of stomachaches and rheumatism.
Recently, the studies have reported that Star anise contents some substances considered antioxidant activities (Kim and Kim, 2003) and significant anti-carcinogenic potential (Yadav and Bhatnagar, 2007). Furthermore, the studies showed that Star anise oil possesses (E)-anethole with concentrating to be about $86.0 \%-93.0 \%$ (Cook and Howard, 1966; Wichtl, 2004). Besides, it contents other compounds such as estragole, pinene, $\beta$-phellandrene, limonene, (Z)-anethole, and $\alpha$-terpineol (Li and Liu, 2000; Cu et al., 1990).

Normal methods applied to extract Star anise fruits'essential oil have been reported such as hydro-distillation, solvent distillation and steam distillation. The traditional method uses steam distillation. The high temperature and hydrolytic effect of water may cause degradation of essential oil (Yan et al., 2002; Reverchon, 1997). Recently, isolated oils from some plants by supercritical fluid $\mathrm{CO}_{2}$ and specialty microwave-assisted extraction have been payed attention to researchers and industries.

\footnotetext{
*Corresponding author:

Dao Thien, Faculty of Food Technology, Ho Chi Minh City University of Food Industry, Vietnam. Phone: (84 8) 38161673 ,

Fax: (84 8) 38163319. E-mail: daothien1980@yahoo.com/thiendao@cntp.edu.vn
}

Received: 20 May 2016;

Revised: 24 January 2017;

Accepted: 28 January 2017;

Published Online: 04 February 2017 
Microwaves have frequencies from $300 \mathrm{MHz}$ to $300 \mathrm{GHz}$, located between the $\mathrm{X}$ and infrared rays in the electromagnetic spectrum (Letellier and Budzinski, 1999). Microwave sharply relies on the dielectric susceptibility not merely the solvent but also solid plant matrix (Zuloaga, 1999). Moreover, there were many reports on applicating of microwave in environmental residues (Letellier and Budzinski, 1999; Zuloaga et al., 1999; Sanghi and Kannamkumarath, 2004; Karthikeyan et al., 2006).

Microwave heating plays an important role in analytical and organic laboratory, a very effective and non-polluting activating method. This method is employed in a variety of fields such as digestion, analytical chemistry, organic synthesis, the food industry and so on. Moreover, microwaveassisted extraction is an alternative to normal techniques and the most economical technique to extract compounds from many plants (Hemwinmon et al., 2007). It can reduce not merely the extraction time but also solvent consumption. On the other hand, it has the potential to improve extraction quality (Pan et al., 2008; Pallaronis et al., 2002).

However, there is not any report published about extracting essential oil from Star anise by microwaveassisted extraction. The extraction by microwave technique possesses its own specific parameters which need to be characterized for different essential oil containing plants.

In this paper, the effects of microwave energy, irradiation time and particle size on extraction of Star anise fruits (Illicium verum Hook. f.) grown in Vietnam will be determined and extraction parameters will be optimised. A Doehlert's protocol will be used to reduce the number of experiments. Doehlert matrices (Doehlert, 1970) are particular experimental designs which represent the advantage of both the variables space and the experimental space (Quignon et al., 1997). Thus, it is possible applied not simply to appreciate the impact of a first set of experiments with a limited number variables but also to carry out another set of experiments where the impact of the remaining variables is evaluated. Furthermore, the selected range of any parameters tested can be enlarged by presenting another set of experiments, without repeating all former experiments. The combined effects will be presented by means of a polynomial model (Taragano and Pilosof, 1999).

\section{MATERIALS AND METHODS}

\section{Collecting sample}

Star anise fruits (Illicium verum Hook. f.) were collected in Lang Son province, Vietnam from September to October, 2014. The fruits were selected from different trees, about 30 plants per lot. The fruits were cleaned to remove soil and other materials. The fruits were stored in plastic box, kept in ice and transported to the laboratory in the same day. The samples were mixed carefully. The moisture content of Star anise has been modified by low-temperature drying. The final moisture content is $11 \%$. Then the fruits were frozen, freezedried and stored at $-53^{\circ} \mathrm{C}$ under nitrogen gas until analysis.

\section{Sample preparation}

The Star anise fruits were grinded into 3 particle size fractions of $0.4 \mathrm{~mm}$ (mesh no.40), $1.2 \mathrm{~mm}$ (mesh no.16) and $2.0 \mathrm{~mm}$ (mesh no.10) (American Standard Sieve Series ASTM E11:95).

\section{Microwave assisted Soxhlet extraction (MASE)}

The equipment operates similarly to a normal Soxhlet extractor with Model: R106S (i.e. the sample is dissolved in fresh, recycled solvent) the sole difference being that the sample receives microwave irradiation over a present period when it is in contact with the extractant. The multimode microwave reactor has a twin magnetron $(2 \times 800 \mathrm{~W}$, $2450 \mathrm{MHz}$ ) with a maximum delivered power of $1000 \mathrm{~W}$ in $10 \mathrm{~W}$ increments. A rotating microwave diffuser ensures homogeneous microwave distribution throughout the plasma coated $(35 \mathrm{~cm} \times 35 \mathrm{~cm} \times 35 \mathrm{~cm})$. The temperature was controlled by feedback to the microwave power regulator. The sample vessel's temperature was controlled with a microwave-inert optical fire temperature probe and it was not exceed $100^{\circ} \mathrm{C}$.

In a typical MASE procedure, $10 \mathrm{~g}$ the Star anise fruits was homogenized and placed in a cellulose thimble, which was capped with cotton wool and put into the cartridge vessel located in the zone of microwave irradiation. This device operates with microwave power from $100 \mathrm{~W}$ to $400 \mathrm{~W}$. The overall Soxhlet glassware was fitted to a distillation flask, containing $100 \mathrm{ml}$ water and two to three boiling glass regulators. Extraction was operated until no more oil was collected and the solvent was released by using a rotaryevaporator and the oil layer was dried by anhydrous sodium sulfate. The yield was expressed as weight percentage of essential oil of raw material Y (r.m).

\section{Steam extraction}

$50 \mathrm{~g}$ sample was submitted to hydro-distillation with a Clevenger-type apparatus and extracted with $500 \mathrm{ml}$ water in the $1000 \mathrm{ml}$ flask about $120 \mathrm{~min}$. The essential oil was collected to cool at room temperature and the volume was read and stored at $4^{\circ} \mathrm{C}$ until used. The yield was expressed as weight percentage of raw material (r.m).

\section{Analysis by gas chromatography - mass spectrometry (Fig. 3) \\ The essential oils were directly analyzed by gas chromatography coupled to mass spectrometry}


(Hewlett-Packard 6890 coupled to a Agilent 5973). The column was a HP-5MS (30 m long, $0.25 \mathrm{~mm}$ and $0.25 \mu \mathrm{m}$ film thickness). The operating conditions were as follows: Flow rate $1.0 \mathrm{~mL} / \mathrm{min}$; injection temperature $250^{\circ} \mathrm{C}$; carrier gas $\mathrm{He}$; split 1:20; injection volume $0.2 \mu \mathrm{L}$; oven temperature progress from $60^{\circ} \mathrm{C}$ to $220^{\circ} \mathrm{C}$ at $5^{\circ} \mathrm{C} / \mathrm{min}$, from $220^{\circ} \mathrm{C}$ to $250^{\circ} \mathrm{C}$ at $10^{\circ} \mathrm{C} / \mathrm{min}$; the ionization mode was electronic impact at $70 \mathrm{eV}$. The constituents in the essential oils were determined by analysing matching of their mass spectral fragmentation patterns with those of compounds in the data bank NIST 98 and Wiley 275 library. Peak normalization method assuming equal detector response has been used to calculate percentage composition. Each sample was duplicated, thus, in total four analyses were performed for extracts for each process. In the percentage compositions with relative standard deviation (R.S.D.) were the average of four analyses.

\section{Experimental design}

An experience was defined with microwave power $(100-400 \mathrm{~W})$, irradiation time $(10-40 \mathrm{~min})$ and particle sizes $(0.4-2.0 \mathrm{~mm})$. Each experiment was performed in triplicate. The Doehlert designs are surface response designs, which use to describe a region around an optimal response with a polynomial relationship and contains $\mathrm{k}^{2}+\mathrm{k}+1$ points for $\mathrm{k}$ variables. For 3 variables, a set of 13 experiments was performed and one of the properties of the design is the uniform distribution in a threedimensional space. Each experiment can be located by its three coded values. Thus, 12 experiments are equidistant from a central experiment having the coded values: $(0,0$, $0)$ and are distributed on an area with a radius of 1.

In this study, the yield Y (r.m) was estimated, taking into account the influences of 3 factors (i.e. variables): Microwave power $\left(\mathrm{X}_{1}\right)$, irradiation time $\left(\mathrm{X}_{2}\right)$, and particle sizes $\left(\mathrm{X}_{3}\right)$.

\section{Analysis and interpretation of the results}

Multiple regression analysis based on least square method was performed by using the software Nemrod (LPRAI, Marseille, France). The analysis concerned the linear and quadratic effects of the three factors and their interactions. Thus, the equation giving $\mathrm{Y}$ was a second-order polynomial model with 10 coefficients $\left(\mathrm{b}_{0}, \mathrm{~b}_{1}, \mathrm{~b}_{12} \ldots \mathrm{b}_{23}\right): \mathrm{Y}=\mathrm{b}_{0}+\mathrm{b}_{1} \mathrm{X}_{1}$ $+\mathrm{b}_{2} \mathrm{X}_{2}+\mathrm{b}_{3} \mathrm{X}_{3}+\mathrm{b}_{11} \mathrm{X}_{1}{ }^{2}+\mathrm{b}_{22} \mathrm{X}_{2}{ }^{2}+\mathrm{b}_{33} \mathrm{X}_{3}{ }^{2}+\mathrm{b}_{12} \mathrm{X}_{1} \mathrm{X}_{2}+$ $\mathrm{b}_{13} \mathrm{X}_{1} \mathrm{X}_{3}+\mathrm{b}_{23} \mathrm{X}_{2} \mathrm{X}_{3}$ where $\mathrm{X}_{1}, \mathrm{X}_{2}$ and $\mathrm{X}_{3}=$ factors studied.

The significance of the coefficients was evaluated by multiple regression analysis based upon the F-test with unequal variance, $\mathrm{P}<0.05(*), \mathrm{P}<0.01\left(^{* *}\right)$ and $\mathrm{P}<0.001$ $(* * *)$. The response curves which have be drawn for two factors by keeping the third factor at its optimal value obtained through using the same software.

\section{RESULTS AND DISCUSSION}

\section{Influence of particle size to yield}

The oil yield distilled for four particle sizes was given in Fig. 1. The results showed that particle size sharply effects on the yield. The oil yield for particle sizes about $0.4 \mathrm{~mm}$ and from 0.4 to $1.2 \mathrm{~mm}$ was not significantly different with both sizes. The highest oil yield was 9.5 (r.m) for particle sizes from 0.4 to $1.2 \mathrm{~mm}$ and particle sizes smaller of $0.4 \mathrm{~mm}$. The slowest distillation was a particle size of whole fruit. The results indicated that Illicium verum Hook. f. could use the smaller particle size about $1.2 \mathrm{~mm}$.

Effects of microwave power, irradiation time and particle sizes on the yield $Y$ (r.m) by microwave assisted Soxhlet extraction

The Y (r.m) values obtained in the various conditions as reported in this paper are presented in Table 1. The

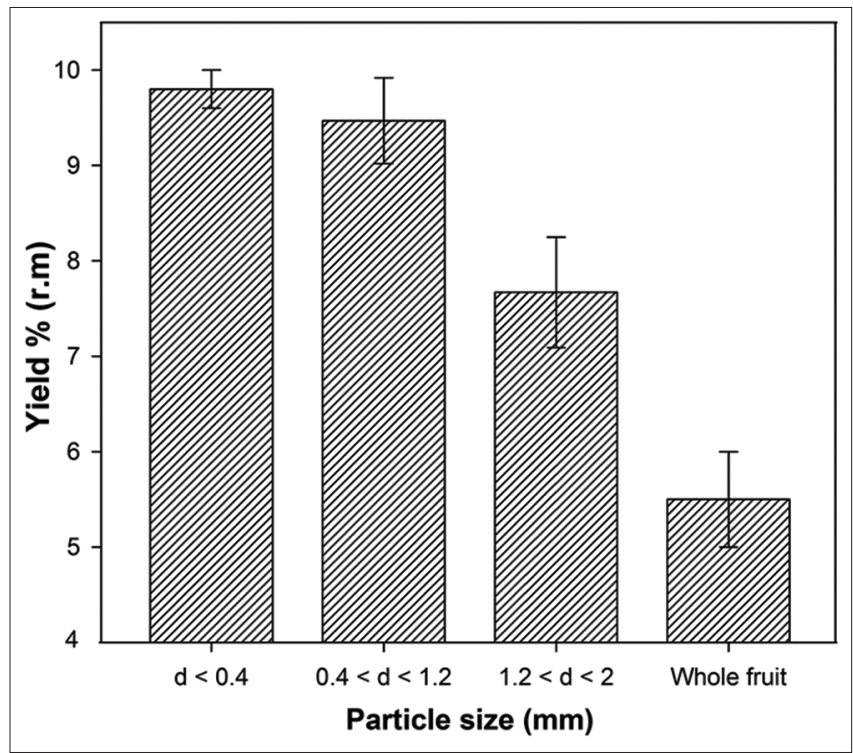

Fig 1. Influence of particle size to yield.

Table 1: Experimental values for Y\%

\begin{tabular}{lcccc}
\hline$N^{\circ}$ Exp & $\begin{array}{c}\text { Microwave } \\
\text { power, } \mathbf{W}\end{array}$ & $\begin{array}{c}\text { Irradiation } \\
\text { time, } \text { min }\end{array}$ & $\begin{array}{c}\text { Particle } \\
\text { sizes, } \mathbf{m m}\end{array}$ & $\begin{array}{c}\text { Yield Y \% (r.m), } \\
\text { mean } \pm \text { sd }\end{array}$ \\
\hline 1 & 400 & 25 & 1.2 & $6.17 \pm 0.29$ \\
2 & 100 & 25 & 1.2 & $4.50 \pm 0.50$ \\
3 & 325 & 40 & 1.2 & $6.17 \pm 0.29$ \\
4 & 175 & 10 & 1.2 & $4.17 \pm 0.29$ \\
5 & 325 & 10 & 1.2 & $5.27 \pm 0.25$ \\
6 & 175 & 40 & 1.2 & $6.27 \pm 0.25$ \\
7 & 325 & 30 & 2.0 & $4.17 \pm 0.28$ \\
8 & 175 & 20 & 0.4 & $6.00 \pm 0.50$ \\
9 & 325 & 20 & 0.4 & $8.30 \pm 0.28$ \\
10 & 250 & 35 & 0.4 & $7.00 \pm 0.00$ \\
11 & 175 & 30 & 2.0 & $3.30 \pm 0.26$ \\
12 & 250 & 15 & 2.0 & $3.37 \pm 0.15$ \\
13 & 250 & 25 & 1.2 & $6.30 \pm 0.25$ \\
\hline
\end{tabular}


experiment number 10 was identical. Moreover, the difference between the assays is $0.1 \%$ for yield Y $\%$ (r.m) less than equal to $1 \%$ for yield. The results of 39 different experiments were ranging from 3.3 to $8.3 \%$ (r.m.). The highest essential oil yield was $8.3 \%$ with microwave power $(325 \mathrm{~W})$, irradiation time $(20 \mathrm{~min})$ and particle sizes $(0.4 \mathrm{~mm})$ from this extraction. As a result, the smaller the particle size was, the faster the extraction of essential oil yields was.

The results of the regression performing model coefficients were listed in the Table 2 . The regression coefficients $\left(\mathrm{r}^{2}\right)$ were about 0.932 . This means that $93 \%$ of the experiments in the matrix could be explained by these models. Moreover, coefficients $\left(b_{0}\right)$ were less different than the experimental values of $\mathrm{Y}$ from all the factors such as the factor 0 in experiment 1 . Furthermore, the greater the absolute value of the linear coefficients (from $b_{1}$ to $b_{3}$ was the more important the variable influencing the response was. Therefore, the particle sizes sharply impact essential oil yield. On the other hand, the particle sizes play more important than the irradiation time on extracted essential oil yield. Besides, the coefficients, $b_{1}$ and $b_{2}$ were positive; this means that the response increases along with increasing the variable. In contrast, the coefficients, $b_{3}$ was negative. In other words, the response declines with increasing the variable. Moreover, irradiation time and microwave power significantly affected on yield $(\mathrm{Y} \%)$. However, values $\left(b_{1}, b_{2}\right.$ and $\left.b_{3}\right)$ could be ranked which depended on their impact to yield Y\% (r.m). To increase yield, the factors must meet the following requirements: Particle sizes $\left(b_{3}=-2.14\right)$, microwave power $\left(b_{1}=0.94\right)$ and irradiation time $\left(b_{2}=0.68\right)$.

The first order interaction coefficient, $b_{23}$ was not significant, Table 2. The negative values for $\mathrm{b}_{11}, \mathrm{~b}_{22}, \mathrm{~b}_{33}$, $b_{12}$ and $b_{13}$ suggest an antagonistic effect were observed on the process of extraction. The interaction coefficients, $\mathrm{b}_{11}, \mathrm{~b}_{22}, \mathrm{~b}_{33}, \mathrm{~b}_{12}$ and $\mathrm{b}_{13}$ were significant.

Table 2: Model coefficients obtained
\begin{tabular}{llcc}
\hline$N^{0}$ & Nom & Coefficient & Signif. \% \\
\hline 1 & $b_{0}$ & 6.27 & $<0.01^{* * *}$ \\
2 & $b_{1}$ & 0.94 & $<0.01^{* * *}$ \\
3 & $b_{2}$ & 0.68 & $<0.01^{* * *}$ \\
4 & $b_{3}$ & -2.14 & $<0.01^{* * *}$ \\
5 & $b_{11}$ & -0.93 & $0.0232^{* * *}$ \\
6 & $b_{22}$ & -0.76 & $0.171^{* *}$ \\
7 & $b_{33}$ & -0.94 & $0.0165^{* * *}$ \\
8 & $b_{12}$ & -0.69 & $0.215^{* *}$ \\
9 & $b_{13}$ & -0.65 & $0.761^{* *}$ \\
10 & $b_{23}$ & 0.44 & 6.0 \\
\hline$* \star *$
\end{tabular}

***Significant $(P<0.01)$; ${ }^{*}$ significant $(P<0.05)$; ${ }^{*}$ significant $(P<0.1)$; ns: Not significant

\section{Model fitting}

By omitting the non-significant coefficients, the reduced equations which described the relationship between the factors and the yield $\mathrm{Y} \%$ (r.m):

$\mathrm{Y} \%$ (r.m) $=6.27+0.94 \mathrm{~W}+0.68 \mathrm{~h}-2.14 \mathrm{P}-0.93 \mathrm{~W}^{2}-$ $0.76 h^{2}-0.94 P_{2}-0.69$ W.h -0.65 W.P

In order to determine the optimum conditions for yield $\mathrm{Y}$ $\%$, surface response contour plots have been drawn. One factor was fixed arbitrarily at the center of the matrix, while the two other factors were varying. By fixing the particle sizes at $1.2 \mathrm{~mm}$, the effect of microwave power and irradiation time on $\mathrm{Y} \%$ was shown on Fig. 2. The optimum conditions were schematized as an ellipse. The center of the ellipse (275 - $350 \mathrm{~W} ; 25$ - $34 \mathrm{~min}$ ) represented the optimum conditions in terms of microwave power and irradiation time at particle sizes equal to $1.2 \mathrm{~mm}$. In these optimum conditions, the model predicted yield $\mathrm{Y} \%$ of essential oil for Illicium verum Hook. $\mathrm{f}$. In order to prevent from essential oil extraction, it was therefore recommended to keep away from these optimum conditions. In the experimental matrices schematised by circles were listed in Fig. 2.

\section{Composition of the essential oils}

The content and the representative composition of the essential oils of Illiciumu verum Hook. f. were pointed in the Table 3. (E)-anethole was the most important compound $(92.43 \%)$. This result was according to the literature (Cook and Howard, 1966; Wichtl, 2004). The composition of

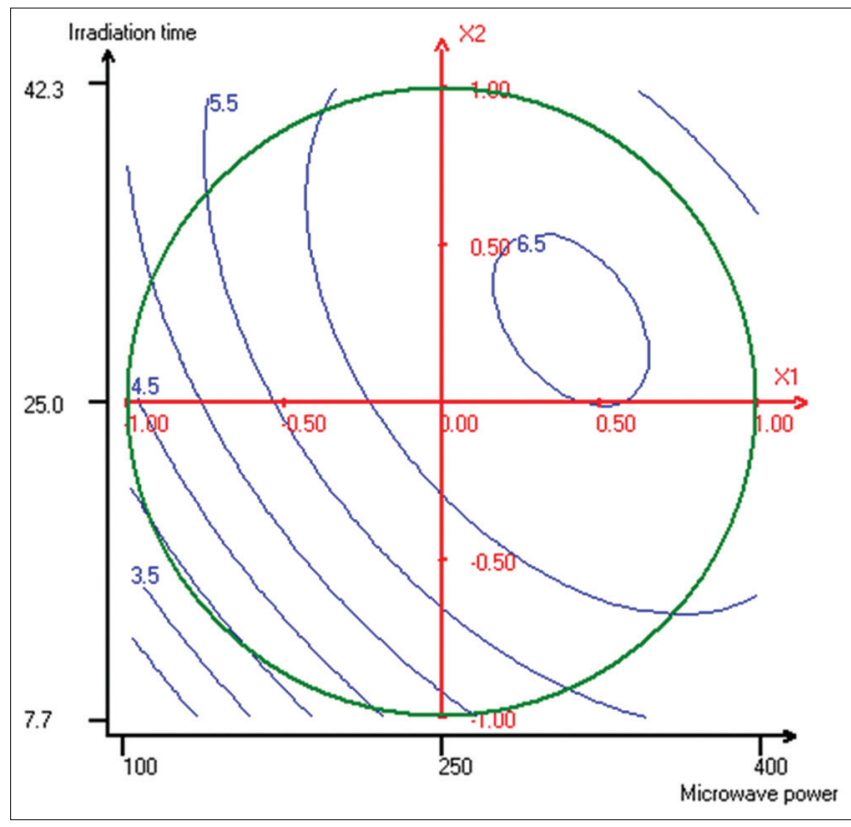

Fig 2. Contour plots of the influence of microwave power and irradation time on Y\% (r.m) of essencial oil for Illicium verum Hook. f. at particle size $=1.2 \mathrm{~mm}$. 
Table 3: Retention time and components and content of essential oils extraction from fruit of Illicium verum Hook. f. by microwave assisted Soxhlet extraction and steam distillation

\begin{tabular}{|c|c|c|c|c|}
\hline \multirow[t]{2}{*}{$\mathbf{N}^{0}$} & \multirow[t]{2}{*}{ Compounds* } & \multirow[t]{2}{*}{ Retention time, min } & \multicolumn{2}{|c|}{ Content $(\%)^{\star *}$} \\
\hline & & & Steam distillation & MASE \\
\hline 1 & $\alpha$-Pinene & 5.40 & $0.70 \pm 0.2$ & - \\
\hline 2 & $\beta$-Myrcene & 6.95 & $0.10 \pm 0.1$ & - \\
\hline 3 & $\alpha$-Phellandrene & 7.37 & $0.24 \pm 0.3$ & - \\
\hline 4 & $\delta$ - 3 - Carene & 7.50 & $0.46 \pm 0.4$ & - \\
\hline 5 & Para - Cymene & 7.95 & $0.20 \pm 0.2$ & - \\
\hline 6 & Limonene & 8.04 & $4.34 \pm 0.6$ & - \\
\hline 7 & 1,8 - cineole & 8.16 & $0.40 \pm 0.1$ & - \\
\hline 8 & Linalool & 10.33 & - & $0.33 \pm 0.1$ \\
\hline 9 & Terpinen-4-ol & 12.90 & - & - \\
\hline 10 & $\alpha$-Tecpineol & 13.14 & $0.14 \pm 0.1$ & $0.01 \pm 0.0$ \\
\hline 11 & 4-Allylanisole & 13.69 & $0.38 \pm 0.2$ & $0.12 \pm 0.1$ \\
\hline 12 & 1-Methoxy-4-(1-propenyl)-benzene & 15.57 & - & $0.14 \pm 0.1$ \\
\hline 13 & Para-Anisaldehyde & 15.63 & $1.84 \pm 0.3$ & $1.65 \pm 0.3$ \\
\hline 14 & (E)-Anethole & 16.91 & $89.19 \pm 0.7$ & $92.43 \pm 0.8$ \\
\hline 15 & $\alpha$-Copaene & 19.50 & $0.16 \pm 0.1$ & $0.15 \pm 0.1$ \\
\hline 16 & 2-Propanol & 19.73 & - & $0.19 \pm 0.1$ \\
\hline 17 & endo-2,6-dimethyl-6- & 20.78 & - & $0.18 \pm 0.2$ \\
\hline 18 & $\beta$-Caryophyllene & 20.87 & $0.20 \pm 0.1$ & $0.19 \pm 0.1$ \\
\hline 19 & Trans- $\alpha$-Bergamotene & 21.43 & $0.55 \pm 0.4$ & $0.46 \pm 0.3$ \\
\hline 20 & Trans-beta-farnasene & 22.13 & - & $0.13 \pm 0.1$ \\
\hline 21 & $\beta$-Bisabolene & 23.65 & $0.19 \pm 0.1$ & $0.14 \pm 0.1$ \\
\hline 22 & 1-(3-metyl-2-butenoxy)-4-(1-propenyl)-benzene & 28.58 & $0.77 \pm 0.3$ & $0.25 \pm 0.2$ \\
\hline 23 & 1-butanol & 33.03 & $0.45 \pm 0.2$ & - \\
\hline 24 & 4-methoxy-benzaldehyde & 33.86 & $0.80 \pm 0.3$ & - \\
\hline
\end{tabular}

${ }^{*}$ As identified by GC-MS software; names according to both NIST 98 and Wiley 275 library, ${ }^{* *}$ Quantitative data were obtained by relating individual peak areas to the total area of the total ion chromatogram

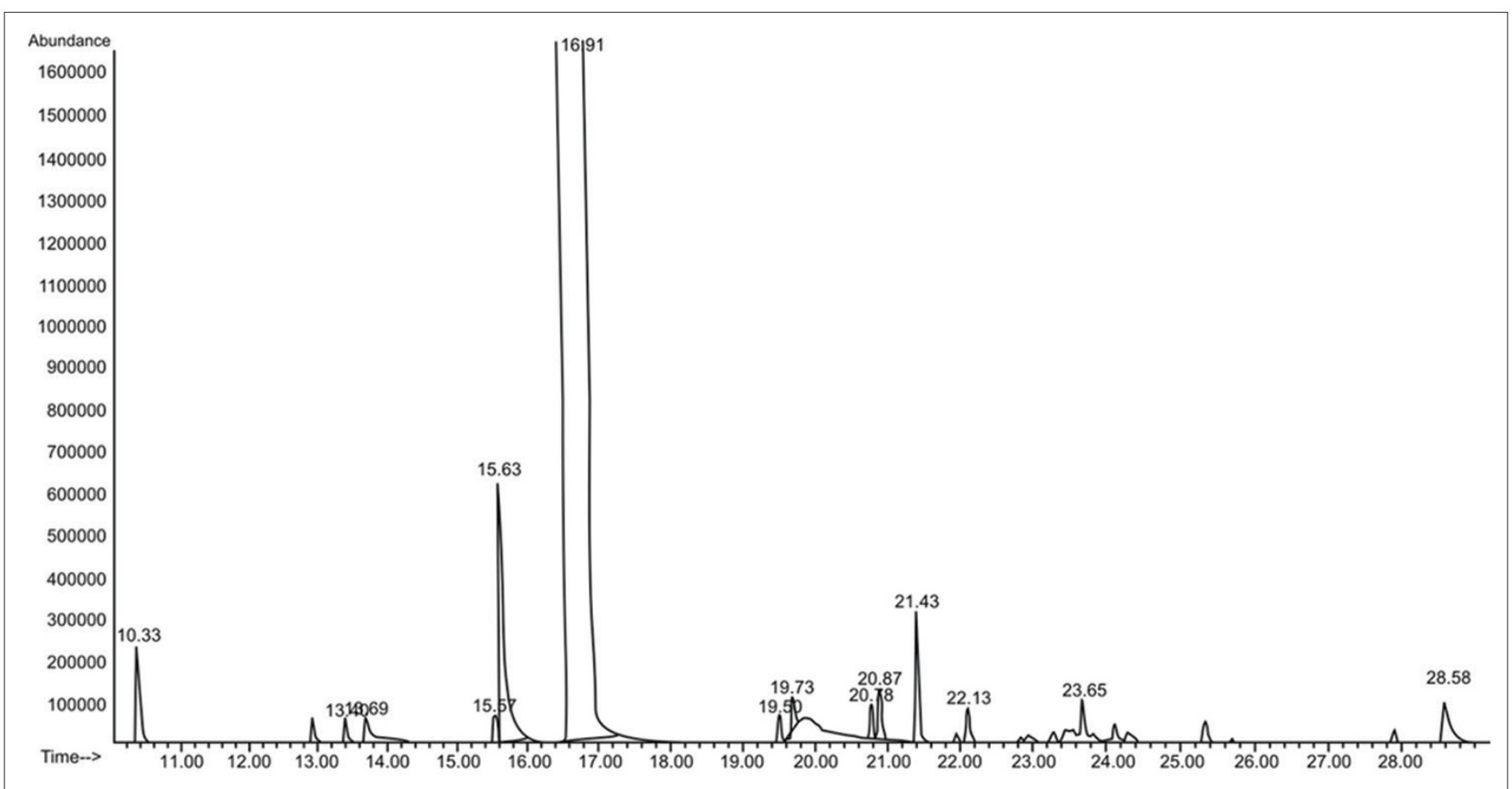

Fig 3. Gas chromatograms of essential oils extraction from fruit of Illicium verum Hook. f. by microwave assisted Soxhlet extraction.

the essential oil extracted from Illicium verum Hook. f. by MASE was used the same as that obtained by other methods. Although there was some difference in the content fraction of identical compounds, the major 
compound, including (E)-anethole were obtained in both methods similarly.

However, the oil's compositions were slightly different in both methods. In fact, if oils are extracted by MASE, some ingredients such as $\alpha$-pinene, $\beta$-mycren, $\alpha$-phelandren will be absent. Although there were not these substances, this slightly impacted the quality of essential oil, because their content in oil is small.

In this study, the performance of microwave assisted Soxhlet extraction (MASE) technique has been showed. It was reported that particle sizes play an important role for yield oil extracted (Dang and Ilangantileke, 1997). Our results were in accordance with these observations, particle size was more important than other factors to yield.

The yield oil using steam distillation and supercritical fluid $\mathrm{CO}_{2}$ extraction from Illicium verum Hook. f. has achieved 10.2 and $11.2 \%$ (r.m), respectively (Dang and Ilangantileke, 1997). In other studies, the essential oil yield by steam distillation was $9.5 \%$ (r.m). This could be explained by the differences of particle sizes.

Interestingly, Wang et al. (2006) showed that with a microwave irradiation power of $85 \mathrm{~W}$, it took only approximately $30 \mathrm{~min}$ to extract the essential oil completely by solvent-free microwave extraction technique. Recently, Zhai et al. (2009) reported that the extraction time was less than $15 \mathrm{~min}$ at the microwave power of $440 \mathrm{~W}$ to compared with those obtained by hydro-distillation when using ionic liquid as microwave absorption medium. In the paper, the highest essential oil yield from microwave assisted Soxhlet extraction was $8.3 \%$ at $325 \mathrm{~W}$ microwave power, $20 \mathrm{~min}$ irradiation time and $0.4 \mathrm{~mm}$ particle sizes. On the other hand, extraction times was very short compared to other methods such as steam distillation or supercritical fluid $\mathrm{CO}_{2}$ extraction. Dang and Ilangantileke (1997) reported that it took $1.5 \mathrm{~h}$ and $4 \mathrm{~h}$ to extract essential oil from Illicium verum Hook. f. by steam distillation or supercritical fluid $\mathrm{CO} 2$ extraction process.

Doelhert models were operated to describe optimal conditions for extraction of essential oil from Illicium verum Hook. F. These methods were significantly suitable to extract essential oils. Previously, polynomial models were used to describe extracted essential oil from Elettaria cardamomum (L) (Lucchesi et al., 2007). The multifactorial analysis was essential to develop a model, an appropriate model to describe possible interaction between the factors

The quality of essential oil obtained by MASE technique was similar to using steam distillation. Moreover, the MASE technique recovered less volatile constituents than conventional distillation but these constituents did not significantly contribute to final profile of flavour such as: $\alpha$ - pinene, $\beta$ - mycren, limonene.

\section{CONCLUSION}

In this work, essential oil was extracted by the microwave assisted Soxhlet extraction methods. The optimal conditions included in the following parameters: Microwave power $325 \mathrm{~W}$, irradiation time $20 \mathrm{~min}$ and particle sizes $0.4 \mathrm{~mm}$. Maximum essential oil yield was $8.3 \%$. The main compound of Illicium verum Hook.f was the (E)-anethole (92\%). Moreover, the results obtained in the study, will provide basic data for further development and application of star anise for food industry. In tropical countries, with variety of vegetation resources, this method was very capable of developing.

\section{ACKNOWLEDGEMENT}

This research is funded by the Foundation for Science and Technology Development of Ton Duc Thang University (FOSTECT), website: http://fostect.tdt.edu.vn, under Grant FOSTECT.2015.BR.10

\section{Author's contributions}

N. N. Phan, L. T. K. Phan and T. H. Tran participated in the experiments and data analysis, T. Dao, the corresponding author designed the research plan, organized the study, and contributed to the writing of the manuscript. M. H Chatain participated in the experimental design and also contributed to the writing of the manuscript.

\section{REFERENCES}

Chempakam, B. and S. Balaji. 2008. Chemistry of Spices, CABI Publishing, London, UK, pp. 319-330.

Claus, E. P. and V. E. Tyler. 1965. Pharmacognosy, 5th ed, Lea and Febiger, Philadelphia, PA.

Cook, W. B. and A. S. Howard. 1966. The essential oil of Illicium anisatum Linn. Can. J. Chem. 44: 2461-2464.

Cu, J. Q., F. Perineau and G. Goepfert. 1990. GC/MS analysis of star anise oil. J. Essent. Oil Res. 2: 91-92.

Dang, Q. T. and G. S. Ilangantileke. 1997. Liquid $\mathrm{CO}_{2}$ extraction of essential oil from Star Anise fruits (Illicium verum $\mathrm{H}$.). J. Food Eng. 31: 47-57.

Doehlert, D. H. 1970. Uniform shell designs. Appl. Stat. 19: 231-239.

Hemwimon, S., P. Pavasant and A. Shotipruk. 2007. Microwaveassisted extraction of antioxidative anthraquinones from roots of Morinda citrifolia. Sep. Purif. Technol. 54: 44-50.

Karthikeyan, S., R. Balasubramanian and S. W. See. 2006. Optimization and validation of a low temperature microwave assisted extraction method for analysis of polycyclic aromatic hydrocarbons in airborne particulate matter. Talanta. 69: 79-86. 
Kim, H. Y. and K. Kim. 2003. Protein glycation inhibitory and antioxidative activites of some plant extracts in vitro. J. Agric. Food Chem. 51: 1586-1591.

Letellier, M., H. Budzinski, L. Charier, S. Capes and A. M. Dorthe. 1999. Optimization by factorial design of focused microwave assisted extraction of polycyclic aromatic hydrocarbons from marine sediment. J. Anal. Chem. 364: 228-237.

Li, S. and S. Liu. 2000. Chemical constituents of essential oil from Cenxi's Illicium. China Condiment. 20: 69-70.

Loi, D. T. and N. V. Thu. 1970. Medicinal Trees and Pharmaceutical Material and Herbs in Vietnam, Pharmacy College Publisher, Hanoi, Vietnam, pp. 209-211.

Lucchesi, M. E., J. Smadja, S. Bradshaw, W. Louw and F. Chemat. 2007. Solvent free microwave extraction of Elettaria cardamomum (L.): A multivariate study of a new technique for the extraction of essential oil. J. Food Eng. 79: 1079-1086.

Nguyen, T. H., M. D. Nguyen and N. T. Le. 2012. Synthesis of mequinole from anis oil under green chemistry conditions. J. Sci. Ho Chi Minh City Univ. Educ. 33: 28-35.

Nguyen, T. M. T., H. Natsuko, T.T. Vu, S. Masayoshi and V.T. Pham. 2010. Study on the essential oil and trans-anethol obtained from summer Vietnamese anise star. J. Sci. Technol. 48: 31-35.

Pallaroni, L., C. V. Holst, C. S. Eskilsson and E. Bjorklund. 2002. Microwave-assisted extraction of zearalenone from wheat and corn. Anal. Bioanal. Chem. 374: 161-166.

Pan, Y. M., K. Wang, S. Q. Huang, H. S. Wang, X. M. Mu and C. H. He. 2008. Antioxidant activity of microwave-assisted extract of longan (Dimocarpus longan Lour.) Peel. Food Chem. 106: 12641270.

Quignon, F., A. Huyard., L. Schwartzbrod and F. Thomas. 1997. Use of Doehlert matrices for study of poliovirus-1 absorption. J. Virol. Methods. 68: 33-44.

Reverchon, E. 1997. Supercritical fluid extraction and fractionation of essential oils and related product. J. Supercrit. Fluid. 10: 1-37.
Sanghi, R. and S. S. Kannamkumarath. 2004. Comparison of extraction method by soxhlet, sonicator and microwave in the screening of pesticide residues from solid matrices. J. Anal. Chem. 59(11): 1032-1036.

Taragano, V. M. and A. M. M. Pilosof. 1999. Application of Doehlert designs for water activity, $\mathrm{pH}$ and fermentation time optimization for Aspergillus niger pectinolytic activities production in solidstate and submerged fermentation. Enzyme Microb. Tech. 25: 411-419.

Wang, Z., L. Wang, T. Li, X. Zhou, L. Ding, Y. Yu, A. Yu and H. Zhang 2006. Rapid analysis of the esential oil from dried Illicium verum Hook. f. and Zingiber officinale Rosc. by improved solvent-free microwave extraction with three types of microwave-absorption medium. Anal. Bioanal. Chem. 386: 1863-1868.

Wei, L. L., R. Hua, M. Li, Y. Huang, S. Li, Y. He and Y. Shen. 2014. Chemical composition and biological activity of star anise Illicium verum extracts against maize weevil, Sitophilus zeamais adults. J. Insect Sci. 14: 80-87.

Wichtl, M. 2004. Herbal Drugs and Phytopharmaceuticals, MedPharm GmbH Scientific Publishers, Stuttgart, Germany.

Yadav, A. S. and D. Bhatnagar. 2007. Chem-preventive effect of star anise in $\mathrm{N}$-nitrosodiethylamine iniated and phenobarbital promoted hepato-carcinogenesis. Chem. Biol. Int. 169: 207-214.

Yan, J., X. Xiao and K. Huang. 2002. Component analysis of volatile oil from Illicium verum. J. Central South Univ. Technol. 9: 173-176.

Zhai, Y., S. Sun, Z. Wang, J. Cheng, Y. Sun, L. Wang, Y. Zhang, H. Zhang and A. Yu. 2009. Microwave extraction of essential oils from dried fruits of Illicium verum Hook. f. and Cuminum cyminum L. Using ionic liquid as the microwave absorption medium. J. Sep. Sci. 32: 3544-3549.

Zuloaga, O., N. Etxebarria, L. A. Fernandez and J. M. Madariaga. 1999. Optimization and comparison of microwave assisted extraction and soxhlet extraction for the determination of polychlorinated biphenyls in soil samples using an experimental design approach. Talanta. 50: 345-357. 